\title{
Ischemia reperfusion induced acute lung injury: Using everything and the kitchen sink
}

\author{
Ashok Muniappan, MD
}

\footnotetext{
From the Division of Thoracic Surgery, Massachusetts General Hospital, Boston, Mass. Disclosures: Author has nothing to disclose with regard to commercial support.

Received for publication Nov 9, 2015; accepted for publication Nov 12, 2015; available ahead of print Dec 15 , 2015

Address for reprints: Ashok Muniappan, MD, Division of Thoracic Surgery, Massachusetts General Hospital, Blake 1570, 55 Fruit St, Boston, MA 02114 (E-mail: amuniappan@partners.org).

J Thorac Cardiovasc Surg 2016;151:870-1

$0022-5223 / \$ 36.00$

Copyright (c) 2016 by The American Association for Thoracic Surgery

http://dx.doi.org/10.1016/j.jtcvs.2015.11.017
}

Severe primary graft dysfunction (PGD) continues to affect approximately $10 \%$ to $30 \%$ of patients shortly after lung transplantation, and is associated with significant morbidity, risk of mortality, and inferior long-term outcomes. ${ }^{1}$ Ischemia-reperfusion injury (IRI) is the presumed pathophysiologic basis of PGD, and represents a complex process with multiple overlapping pathways of injury. ${ }^{2}$ The fact that no specific and effective therapy is available to counteract PGD is dismaying, despite the elucidation of numerous biochemical mechanisms of IRI.

Hashimoto and colleagues, ${ }^{3}$ from the Division of Thoracic Surgery at Toronto General Hospital, report their finding that a biologic agent, recombinant human Diannexin V, a homodimer of annexin V, ameliorates IRI in a rat lung transplant model. The authors administered the agent to the donor before procuring the lung, and to the recipient shortly after reperfusion. They observed significantly enhanced graft function, with improved oxygenation and carbon dioxide clearance, as well as a reduction in peak airway pressure. A mechanistic explanation for the observed benefits of the homodimer was suggested by the finding of a reduction in: fibrin deposition, markers of apoptosis, and release of inflammatory cytokines.

The challenge remains of how best to translate the results of this encouraging animal study into meaningful clinical outcomes. The field of IRI is replete with examples of promising strategies that seemingly solve the problem in experimental models, only to fall short in randomized clinical trials. ${ }^{4,5}$ Hashimoto and colleagues ${ }^{3}$ are optimistic about this agent, as it targets a very proximal event in IRI - the translocation of phosphatidylserine to the cell membrane.

The authors are correct to point out promising results with this agent in a phase II study of kidney transplantation, although the results of a follow-up phase II/III trial have yet to be made available. The hurdles to be overcome before the agent is clinically applicable in lung transplantation are likely to be high, given the substantial redundancy built

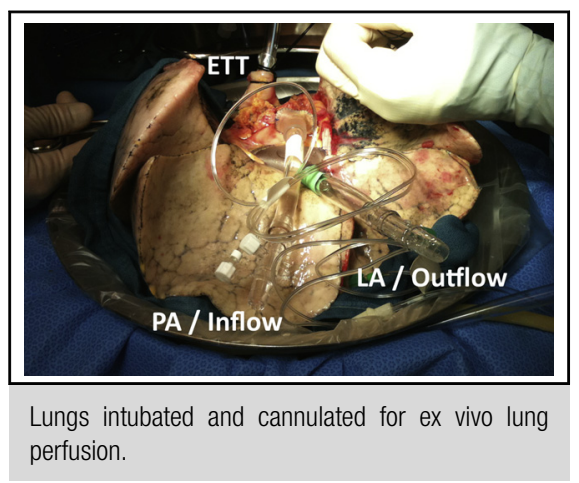

\section{Central Message}

Pharmacologic management of ischemic reperfusion injury in lung transplantation remains challenging.

See Article page 861 .

into pathways operating in IRI, as well as the complex interplay with other donor and recipient factors. Even more intimidating is the immense effort and expense required to test compounds in clinical trials.

The group at Toronto General Hospital is well positioned to surmount some of these challenges. A seminal and recent contribution of the group is the development and clinical utilization of extended normo-thermic ex vivo lung perfusion of lung allografts ${ }^{6}$ (Figure 1). Evaluation, and possibly reconditioning, of lungs previously considered unsuitable for transplantation, is now an opportunity. ${ }^{7}$ Compounds such as this homodimer can be added easily to the perfusate,

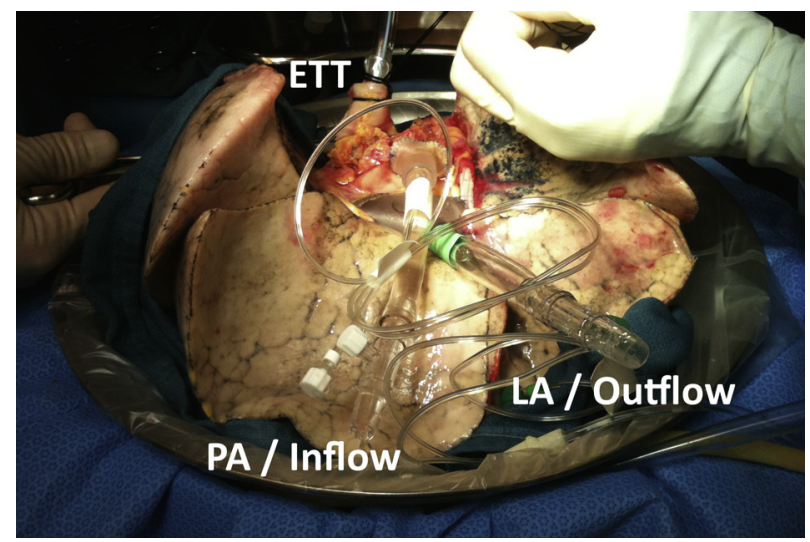

FIGURE 1. Lungs intubated and cannulated for ex vivo lung perfusion. $E T T$, Endotracheal tube; $P A$, pulmonary artery; $L A$, left atrium. 
and tested for their effect on reperfusion ex vivo. Additionally, the necessity of simultaneous targeting of multiple pathways of IRI is quite plausible, as is the possibility that combination therapy tested in the "kitchen sink" of ex vivo lung perfusion will lead to successful clinical trials. Well designed animal studies, such as the one by Hashimoto and colleagues, ${ }^{3}$ will spur further development of agents and strategies to combat IRI in lung transplantation.

\section{References}

1. Christie JD, Kotloff RM, Ahya VN, Tino G, Pochettino A, Gaughan C, et al. The effect of primary graft dysfunction on survival after lung transplantation. Am J Respir Crit Care Med. 2005;171:1312-6.
2. de Perrot M, Liu MY, Waddell TK, Keshavjee S. Ischemia-reperfusion-induced lung injury. Am J Respir Crit Care Med. 2003;167:490-511.

3. Hashimoto K, Kim H, Oishi H, Chen M, Iskender I, Sakamoto J, et al. Annexin V homo-dimer protects against ischemia reperfusion-induced acute lung injury in lung transplantation. J Thorac Cardiovasc Surg. 2016;151:861-9.

4. Meade MO, Granton JT, Matte-Martyn A, McRae K, Weaver B, Cripps P, et al. A randomized trial of inhaled nitric oxide to prevent ischemia-reperfusion injury after lung transplantation. Am J Respir Crit Care Med. 2003;167:1483-9.

5. Keshavjee S, Davis RD, Zamora MR, de Perrot M, Patterson GA. A randomized, placebo-controlled trial of complement inhibition in ischemia-reperfusion injury after lung transplantation in human beings. J Thorac Cardiovasc Surg. 2005; 129:423-8.

6. Cypel M, Yeung JC, Liu M, Anraku M, Chen F, Karolak W, et al. Normothermic ex vivo lung perfusion in clinical lung transplantation. $N$ Engl J Med. 2011;364: 1431-40.

7. Cypel M, Keshavjee S. Extending the donor pool: rehabilitation of poor organs. Thorac Surg Clin. 2015;25:27-33. 